\title{
Evaluating Simulation Model Based on Generated Weather Data
}

\author{
Shijuan Li and Yeping Zhu \\ Laboratory of Digital Agricultural Early-warning Technology of Ministry \\ of Agriculture of China; Institute of Agricultural Information, CAAS, \\ 100081 Beijing, China \\ \{lishijuan, zhuyp\} @mail. caas.net.cn
}

\begin{abstract}
The daily weather series simulated with observed weather data and weather data generated with conventional WGEN model taking dry and wet day as stochastic parameter and DWS model were statistically compared and analyzed. These three weather data were respectively used to drive maize growth simulation model. The corresponding yield results were compared. The results showed there was no significant difference between observed weather data and weather data generated with DWS model. The difference between yield simulated with DWS model and yield simulated with WGEN model was not significant.
\end{abstract}

Keywords: Weather generator, Dry and wet spell, Growth simulation.

\section{Introduction}

Crop growth simulation is to analyze the growth and development mechanism and the quantitative relationship with environment with the help of computer [1-4]. The dynamic processes of crop growth and development are expressed by mathematical methods. Crop simulation model evolves with the development of computer technique, systemic analysis theory and agricultural research achievements. It is the core of precise agriculture and information agriculture, furthermore is the foundation of agricultural production management and resources optimization.

Agriculture is a complicated huge system with many controllable objects. The development and application successively of crop models promoted the change from qualitative description to quantitative analysis for crop growth and development discipline, established good foundation for development of crop growth decision system. The mature models of developed countries had been applied in many fields such as yield estimation, drought evaluation and variety breeding under deferent environments. As a research tool, crop simulation model plays an important role in the domains of environment, resource, continuous development and climate change impacts etc.

Besides solar radiation and temperature, crop simulation considers water and fertilizer restrict too. Disease, insect pest, weeds and other biological factors will be evolved in great simulation model. Many of the factors are linked with weather and management measures. Lack of accurate and timely weather data restricts the regional and large-scale application of crop simulation model. 
Weather generator provides an effective measure and tool for weather data simulation. Weather simulation is to generate weather data in common use such as daily maximum temperature, daily minimum temperature, rainfall and solar radiation based on the observed historical weather materials. The common methods applied are stochastic process theory, probability theory and statistics. When there is no enough observed weather data in certain region, weather generator can provide daily meteorologic materials with parameter interpolation method.

International researches on weather generator began in the 1960s. For China it was in the 1980s [5-7]. The main works were to introduce the foreign weather models to test their simulation effects and improve the model parameters. Weather Generator of NCC/RCC-WG that can simulate four parameters of rainfall, maximum temperature, minimum temperature and sunshine duration was developed by National Climatic Data Center, China Meteorological Bureau. Now only the simulation effect about rainfall was reported, and there was no comparison with other weather generators [8]. Shen et al exploited their own weather generator to drive vegetable disease popularity model and construct insect dynamic diversification [9]. This weather generator is limited to laboratory, and has not been applied and test in a large scale.

\section{Weather Generators Used in This Study}

\subsection{WGEN Model}

The WGEN model is a common used weather generator based on the time series stochastic process constructed by Richardson et al [10]. The precipitation component of WGEN is a two-parameter Markov chain and gamma distribution model. The occurrence probability of wet or dry days is determined, and the precipitation is generated independently of the other variables for a given day. The residual of the three variables of daily values of maximum and minimum temperature and solar radiation are generated using a multivariate normal generation procedure. The WGEN model offers daily values for rainfall, maximum and minimum temperature, and solar radiation for an n-year period at a given location.

\subsection{DWS Weather Generator}

For WGEN model a given day is wet or dry depends on the Markov chain. So the bigger statistic error of dry and wet spell is gotten. DWS model adopts dry and wet spell but not dry and wet day as stochastic parameter. This is the essential difference with WGEN model. Researcher had studied the statistical discipline of dry and wet spell $[11,12]$. The modeling approach and test results were listed in reference [13].

\section{Maize Growth Simulation Model}

Making use of programming language Visual $\mathrm{C}++$ and Visual Basic 6.0 on the operation system of Windows 2000 server, Digital Maize Planting and Management 
System was designed in accordance with maize growth and development discipline using technologies of system engineering theory, software engineering theory, computer and animation and image processing [14]. The system consists of cooperative models, database and interface etc. The main cooperative models contain maize growth model, maize development, water balance model, nitrogen balance model, and 3D visualization model which lay out maize growth and yield formation process. Database was built in Access 2000, and forms and graphs output was carried out by Teechart control unit. In addition, databases, variety parameter test module and weather creation module programmed by Visual $\mathrm{C}++$ are included. Basic parameter database consists of information about location, fertilizer type, fertilizer management, irrigation management, cultivation variety, phenology data, soil texture and soil parameter. Weather data day by day are kept in weather database. The simulation and predicting results of models were transported into result database. Interface functions implement the data transfer between models and databases.

The system simulates several kinds of production fashions, i. e. experiential irrigation, optimal irrigation, no fertilization, no irrigation, rainfall agriculture, potential crop production. This paper uses the production fashion of experiential irrigation to test the weather generation. We run the system according to the irrigation and fertilization amounts commonly applied by farmer, then compared the deference between simulation yield and observed yield.

\section{$4 \quad$ Results Analysis}

For this study, two sites were selected that have weather stations with long-term reliable historical daily data. They include Beijing and Zhengzhou. For each location, daily solar radiation, precipitation, and maximum and minimum temperature were available for 31 years (1973-2003). The day with daily precipitation greater than 0.1 $\mathrm{mm}$ is set as wet day, contrarily as dry day. At first, two 100-year daily weather data generated by WGEN and DWS models respectively was analyzed. Then Digital Maize Planting and Management System was run making use of the observed, generated weather data by above two models to compare the yield difference.

\subsection{Weather Data Simulation Results Analysis}

DWS model simulated weather series well. There was no significant difference between simulated monthly statistics and observed values at the level of 0.01 . Table 1 showed that the absolute error for monthly maximum temperature generally was less than $0.2^{\circ} \mathrm{C}$ at two sites. The highest simulation error was in January, Zhengzhou, but didn't exceed $0.8^{\circ} \mathrm{C}$. The absolute errors for monthly minimum temperature generally were less than $0.2^{\circ} \mathrm{C}$ at two sites. The simulation errors of January, July and August in Zhengzhou exceeded $0.4^{\circ} \mathrm{C}$, but were less than $0.6^{\circ} \mathrm{C}$. In general the absolute errors for monthly precipitation day were less than 1 day. For monthly total solar radiation, the simulation effect difference of DWS and WGEN models is minor. Overall, simulation results for Beijing site were better than Zhengzhou site. 
3
$Z$
3

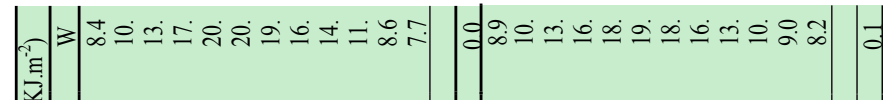

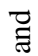

$\hat{e}$

管

言

离

高

o

嗬

离

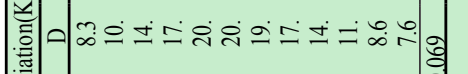

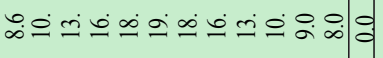

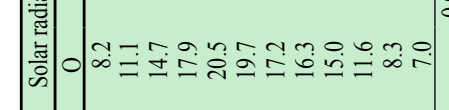

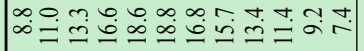

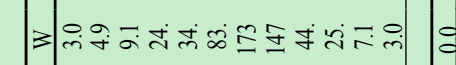

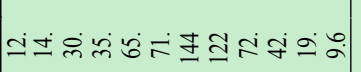
军

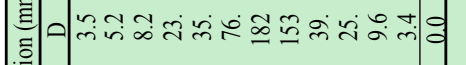

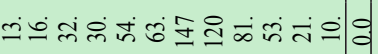

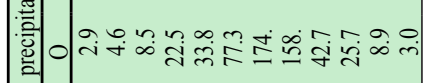

ํํㄹํำ :

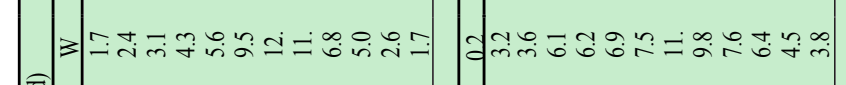
하

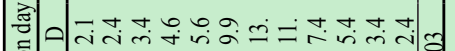
$\operatorname{rid}$ 
Table 1 also showed that DWS model got the similar effect with WGEN model. All the absolute errors for monthly maximum and minimum temperature between DWS model and WGEN model was less than $0.4^{\circ} \mathrm{C}$. The absolute errors of monthly precipitation day were less than $1.5 \mathrm{~d}$, and the errors of average monthly precipitation day were less than $0.5 \mathrm{~d}$. The absolute errors of monthly precipitation were less than 3 $\mathrm{mm}$ at Beijing site except for July and August. For Zhengzhou site the value was 5 $\mathrm{mm}$, but didn't exceed $10 \mathrm{~mm}$. the average monthly precipitation difference between the two models was less than $3 \mathrm{~mm}$. the difference of solar radiations generated by DWS and WGEN was under $0.3 \mathrm{KJ} \bullet \mathrm{m}^{2}$.

\subsection{Analysis of Simulation for Maize Yield}

We run the digital maize plant and management system with the observed and generated weather data by DWS and WGEN to test the influence of irrigation period on maize yield. Four irrigation periods were set, i. e. 1st July, 10th July, 20th July, 30th July. The irrigation amount was $100 \mathrm{~mm}$. The simulation sites were Beijing and Zhengzhou. Maize variety of Nongda 108 was used. Table 2 is the t value $(p=0.05)$ between yield simulated with observed weather data versus generated weather data based on DWS or WGEN. We can see that there was no significant difference between observed yield and simulated yield by DWS or WGEN.

Table 2. $\mathrm{t}$ values between yield simulated with observed weather data versus generated weather data based on DWS or WGEN $\left(\mathrm{t}_{0.05}=2.595, \mathrm{df}=129\right)$

\begin{tabular}{lccc}
\hline \multicolumn{1}{l}{ Sites } & Irrigation period & DWS-Observed & MG-Observed \\
\hline \multirow{3}{*}{ Beijing } & $1^{\text {st }}$ July & 0.2 & 0.936 \\
& $10^{\text {th }}$ July & 0.154 & 0.843 \\
& $20^{\text {th }}$ July & 0.103 & 0.557 \\
& $30^{\text {th }}$ July & 0.944 & 0.341 \\
& & & \\
& $1{ }^{\text {st }}$ July & 0.011 & 0.392 \\
\multirow{2}{*}{ Zhengzhou } & $10^{\text {th }}$ July & 0.011 & 0.318 \\
& $20^{\text {th }}$ July & 0.022 & 0.301 \\
& $30^{\text {th }}$ July & 0.027 & 0.256 \\
\hline
\end{tabular}

From figure 1 we got the yields simulated with generated weather data by DWS or WGEN were all higher than that with observed weather data. The yields simulated with generated weather data by WGEN were very similar with observed weather data. With the delay of irrigation period, all the maize yields simulated with three sources of weather data increased gradually. Jointing stage in July is the key stage for maize growth. Irrigation in this stage is advantageous to grain increase. But July belongs to rainy season, so rainfall may weaken the yield increase extend. 


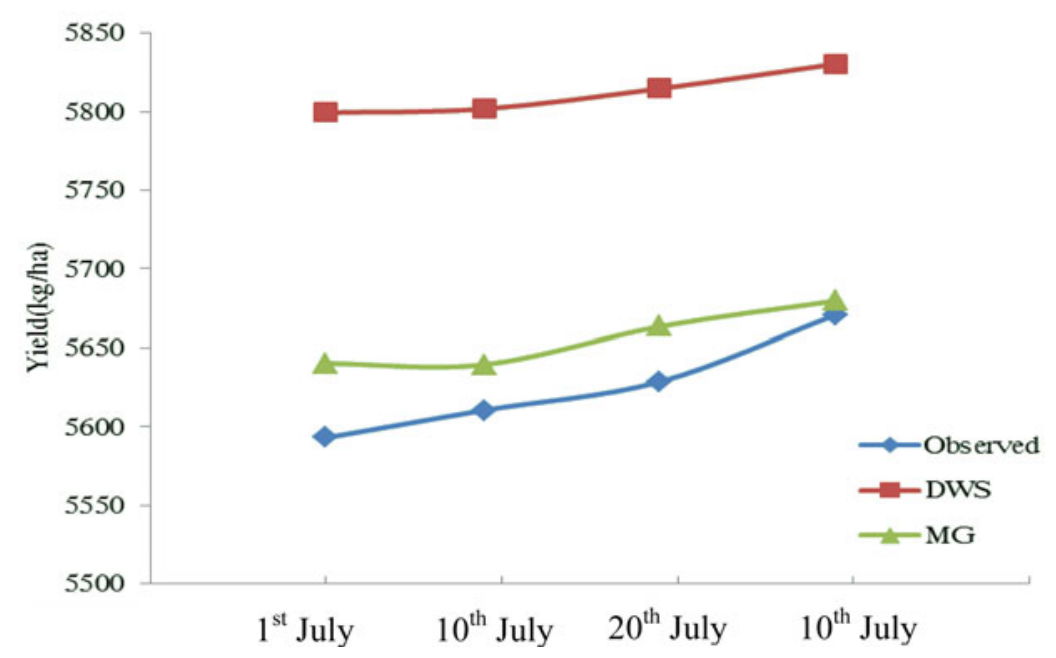

Fig. 1. Response of grain yield to irrigation period for maize simulated with observed weather data and weather data generated with DWS or WGEN

\section{Conclusion}

This paper introduced the DWS model taking dry and wet spell as stochastic parameter, compared statistically the weather data generated with DWS and WGEN. There was no significant difference between observed weather data and generated data. Three source of weather data were used to run the digital maize plant and management system to simulate maize yield. And different irrigation periods were set to test the influence on maize yield. The results showed there was no significant difference between observed yield and simulated yield by DWS or WGEN. The yields simulated with generated weather data by DWS or WGEN were all higher than that with observed weather data. The yields simulated with generated weather data by WGEN were very similar with observed weather data. With the delay of irrigation period, all the maize yields simulated with three sources of weather data increase gradually.

Acknowledgments. This research is kindly supported by Special Fund of Basic Scientific Research and Operation Foundation for Commonweal Scientific Research Institutes and Beijing Nova program.

\section{References}

1. Williams, J.R., Jones, C.A., Kiniry, J.R., et al.: The EPIC Crop Growth Model. Trans. ASAE 32(2), 497-511 (1989)

2. McCown, R.L., Hammer, G.L., Hargreaves, J.N.G., et al.: APSIM: a novel software system for model development, model testing and simulation in agricultural systems research. Agricultural Systems 50, 255-271 (1996) 
3. Gao, L.Z., Jin, Z.Q., Huang, Y., et al.: Rice Cultivational Simulation-OptimizationDecision Making System (RCSODS). China Agricultural Scientech Press, Beijing (1992) (in Chinese)

4. Zhao, C.J., Zhu, D.H., Li, H.X., et al.: Study on intelligent expert system of wheat cultivation management and its application. Scientia Agricultura Sinica 30, 42-49 (1997) (in Chinese)

5. Chen, M.C., Zhang, Q., Yang, J.L.: Stochastic simulationmodeland its verification of precipitation, temperature and sunshining hours. Agricultural Research in the Arid Areas 12(2), 17-26 (1994) (in Chinese)

6. Wu, J.D., Wang, F.T.: Study on the creation of daily climatic variation scenarios with a stochastic weather generator and various interpolations. Quarterly Journal of Applied Meteorology 11(2), 129-136 (2000) (in Chinese)

7. Zhu, Y.P., Wang, S.Q.: Stochastic Modeling of Daily Weather and Its Implementation in Java. Acta Electronica Sinica 12, 2267-2271 (2007) (in Chinese)

8. Liao, Y.M., Zhang, Q., Chen, D.L.: Precipitation simulation in China with a weather generator. Acta Geographica Sinica 59(5), 689-698 (2004) (in Chinese)

9. Ma, X., Shen, Z.: Visual programming stochastic weather generator and its applications to ecological study in future. Scientia Agricultura Sinica 35(12), 1473-1478 (2002) (in Chinese)

10. Richardson, C.W., Wright, D.A.: WGEN: A model for generating daily weather variables. USDA, ARS-8 Washington, DC (1984)

11. Jorgenson, D.L.: Persistency of rain and no-rain periods during the winter at San Francisco. Mon. Weather. Rev. 77(9), 303 (1949)

12. Gabriel, K.R., Neumann, J.: On distribution of weather cycles by length. Quart. J. R. met. Soc. 83, 357-375 (1957)

13. Wang, S.Q., Zhu, Y.P., Li, S.J.: Stochastic simulation for dry and wet spell. Journal of Applied Meteorological Science 20(2), 179-185 (2009) (in Chinese)

14. Li, S.J., Zhu, Y.P., Yan, D.C.: Study on digital maize management system based on model. In: Progress of Information Technology in Agriculture: Proceeding on Intelligent Information Technology in Agriculture(ISSITA), pp. 240-243. China agricultural science and technology press, Beijing (2007) 